\title{
Onboard intelligent system of electric vehicle
}

\section{Nasibulov Il'shat Raisovich}

Russian Federation, Undergraduate Student, Department of «Automated Control Systems».

Moscow Automobile \& Road construction State Technical University, 125319, Russian Federation, Moscow, Leningradsky prospekt, 64. Tel.: +7 (499) 151-64-12. http://www.madi.ru

\section{travuga@yandex.ru}

\begin{abstract}
In recent times there is a question about the future of electric vehicles. Many companies are developing in creating smart car on electricity. In the article the question of creating an electric board intelligent system was discussed. By reviewing domain consider products ana-logues and concluded the feasibility of establishing its own system. Structural composed of the hardware and software of intelligent system, the analysis of the functional part were created. Proposed solutions to the problems met by the intelligent system. Also the choice of the hard-ware platform system was proposed and justified. Produced review can be used in the produc-tion of their own intellectual electric systems. The proposed system can be greatly expanded in functionality, these developments can be used as a basis to create a unified system of intellectu-al electric car.
\end{abstract}

Keywords: intelligent systems, electric vehicle, Controller Area Network (CAN), intelligent system, information, microcontroller, algorithm, differential gear, program. 
ISSN 2306-1561

Автоматизация и управление в технических системах (АУТС) 2014. - №1.1(8). - С. 74-83.

DOI: $10.12731 / 2306-1561-2014-1-8$

\section{УДК 004.8}

\section{Бортовая интеллектуальная система электромобиля}

\section{Насибулов Ильшат Раисович}

Российская Федерация, магистрант кафедры «Автоматизированные системы управления».

ФГБОУ ВПО «Московский автомобильно-дорожный государственный технический университет (МАДИ)», 125319, Российская Федерация, г. Москва, Ленинградский проспект, д.64, Тел.: +7 (499) 151-64-12, http://www.madi.ru

\section{travuga@yandex.ru}

Аннотация. В последнее время все чаще встает вопрос о будущем электромобилей. Многие компании ведут разработки в создании умного автомобиля на электрической тяге. В статье рассмотрен вопрос создания бортовой интеллектуальной системы электромобиля (БИСЭ). Произведен обзор предметной области, рассмотрены продукты-аналоги и сделан вывод о целесообразности создания собственной системы. Составлены структурные схемы аппаратной и программной части интеллектуальной системы, произведен анализ функциональной части. Предложены варианты решения задач, предъявляемые к интеллектуальной системе. Также предложен и обоснован выбор аппаратной платформы системы. Произведенный обзор может быть использован при производстве собственных интеллектуальных систем электромобиля. Предложенная система может быть существенно расширена по функционалу. Произведенные наработки могут быть использованы в качестве основы по созданию единой интеллектуальной системы электромобиля.

Ключевые слова: интеллектуальные системы, электромобиль, сеть контроллеров, интеллектуальная система, информация, микроконтроллер, алгоритм, дифференциал, программа.

\section{1. Введение}

Интеллектуальная система - это комплекс программных и технических средств для решения сложных задач, требующих анализа исходных данных и принятия решения без участия человека [6 - 10]. 
Существует множество интеллектуальных систем, связанных с автомобилями: антипробуксовочная система, интеллектуальная система полного привода, антиблокировочная система и т.д. Ведущие автомобильные концерны тратят большие средства на создание этих систем [7, 8]. Они повышают безопасность, удобство и скорость вождения. Говоря о тенденциях развития автомобилестроения в мире, следует также отметить постепенный переход к технологии электромобилей. Электрическая тяга является более экологичной и безопасной технологией по сравнению с двигателями внутреннего сгорания. При должном управлении, электродвигатели могут обеспечить хорошую динамику, управляемость и плавность вождения.

Одним из приоритетных направлений деятельности автомобилестроения является создание умного электромобиля, способного на основе данных о скорости, ускорения, повороте руля, положении педали газа и т.д. осуществлять интеллектуальное управление моментом силы на каждом из колес. Существует несколько моделей автомобилей, являющимися представителями данного класса. В российском также ведутся свои разработки, но они, как правило, не так сильно развиты, как в странахлидерах. Следовательно, в данном сегменте рынка существует потребность в собственных исследованиях и открытиях, в разработке бортовой интеллектуальной системы электромобиля. Одним из проектов, проводящих исследования в этом направлении, является студенческий проект Formula SAE.

Formula SAE - некоммерческие международные студенческие соревнования по проектированию, постройке и бизнес-презентации гоночных болидов. Данные болиды имеют формульный стиль строения кузова, открытые арки колес, различные типы двигателей: двигатель внутреннего сгорания, гибридные двигатели и электродвигатели. Проектирование болидов производится в соответствии с регламентом соревнований, содержащим в себе много пунктов.

При постройке электрического болида обычно используются два электродвигателя, соединенных непосредственно с колесами. Для управления двигателями необходим компонент, осуществляющий сбор сигналов с датчиков, их фильтрацию, обработку, и, на основе полученных данных, логически управлять силовой частью. В роли такого компонента обычно выступает бортовой компьютер. Есть несколько вариантов решения вопроса, какую бортовую систему использовать: можно воспользоваться либо готовым решением, либо спроектировать и разработать собственную систему. Каждый вариант имеет свои плюсы и минусы.

\section{2. Краткий обзор технических решений для построения автомобильных интеллектуальных систем}

Бортовой компьютер - многофункциональное устройство, выполняющее роль главного вычислительного центра автомобиля. Он осуществляет сбор сигналов с датчиков, их обработку, вывод информации на приборную панель, а также логическое управление силовой частью.

Другими словами, бортовой компьютер «знает» текущие показатели автомобиля, в частности такие параметры, как скорость, угол поворота руля, положение педали газа, 
и на основе этих данных принимает решение об управлении ведущими колесами. В качестве дополнения эти показатели в доступной форме выводятся на приборную панель.

Логическое управление силовой частью сводится к имитации работы механического дифференциала. Необходимость применения дифференциала в конструкции автомобилей обусловлена тем, что внешнее колесо при повороте проходит более длинную дугу, чем внутреннее. То есть при вращении ведущих колёс с одинаковой скоростью поворот возможен только с пробуксовкой, а это негативно сказывается на управляемости и сильно повышает износ шин. В случае использования одного двигателя проблема решается установкой механического дифференциала. Если же используется два двигателя, то можно вообще обойтись без механизма дифференциала, но, в этом случае, при повороте один из двигателей будет испытывать лишнюю нагрузку. Поэтому бортовой компьютер должен учитывать, находится ли машина в повороте, и, следовательно, подавать разные моменты на колеса.

Обмен информацией между основным вычислительным центром и блоками управления двигателями происходит по протоколу Controller Area Network (CAN). CAN - стандарт де-факто по связи электронных компонентов в автомобиле. Промышленная сеть CAN была создана в конце 80-х годов фирмой Bosch как решение для распределенных систем, работающих в режиме реального времени. Первая реализация CAN применялась в автомобильной электронике, однако сейчас CAN находит применение практически в любых типах машин и промышленных установок, от простейших бытовых приборов до систем управления ускорителями элементарных частиц. В настоящий момент CAN-протокол стандартизован в международном стандарте ISO 11898.

В настоящее время разработано множество электронных устройств, представляющих из себя готовые реализации бортового компьютера $[1$ - 10]. Множество автомобильных компаний используют свои разработки в своей продукции. Эти системы закрыты для конечного пользователя, их нельзя изменить, а если и можно, то только с помощью специального оборудования. Также существуют модули сторонних производителей, эти устройства имеются в свободной продаже, они представляют собой готовые аппаратно-программные средства. Такие системы производит, например, компания National Instruments. Если проанализировать ассортимент этой компании, то можно отметить высокую стоимость ее продукции (около 3000\$), а также некую избыточность в плане производительности.

Как правило, все бортовые системы состоят из таких компонентов, как центральный процессор, электронная обвязка, набор датчиков и порты для подключения к внешним устройствам. Отличительной особенностью данных систем является их компактность и рациональность. Это означает, что в качестве ЦП используется не дорогостоящий и мощный процессор, а относительно маломощный микроконтроллер.

Ввиду сказанного выше можно утверждать, что основная стоимость готовых бортовых компьютеров состоит в программном обеспечении, так как аппаратная часть 
не так дорога. Высокая цена ПО объясняется эксклюзивностью разработки автомобильных компаний. Поэтому, в целях экономии средств, было решено разработать собственную бортовую интеллектуальную систему автомобиля.

\section{3. Структурная схема интеллектуальной системы}

Для разработки системы необходимо составить структурную схему ИС. Разрабатываемая ИС физически состоит из следующих компонентов: микроконтроллер, датчики и приборная панель. Микроконтроллер отвечает за обработку данных с датчиков, управление двигателями, «электронный» дифференциал и вывод информации на приборную панель. Датчики собирают информацию о состоянии автомобиля, приборная панель выводит информацию, управляет информационной системой. Структурная схема аппаратной части показана на рисунке 1.

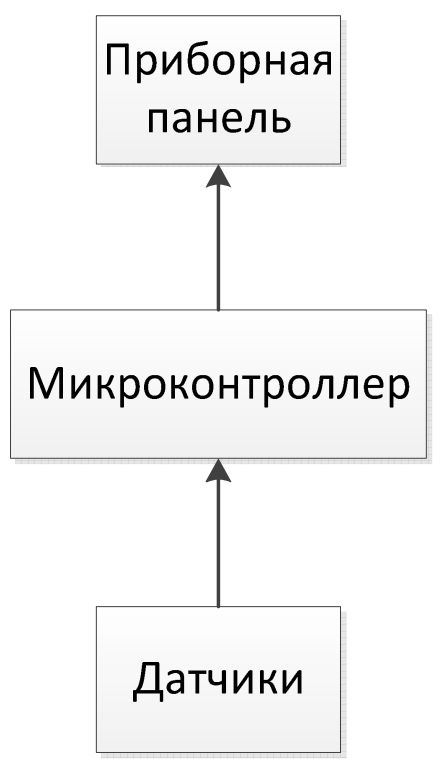

\section{Рисунок 1 - Структурная схема аппаратной части}

С точки зрения программной части проектируемая ИС содержит в себе модуль инициализации периферийных устройств, модуль обработки сигналов, модуль фильтрации данных, алгоритм электронного дифференциала, модуль отправки сообщений и модуль вывода информации на приборную панель. Функционально они связаны следующим образом: модуль инициализации устройств настраивает необходимые регистры, после чего запускается работа этих устройств. Полученные с датчиков данные поступают в модуль обработки данных, затем они фильтруются, после чего происходит расчет значения акселерации на каждое колесо согласно алгоритму дифференциала и происходит передача сообщений с рассчитанными значениями блокам управления двигателями. В конце производится вывод информации на приборную панель.

Структурная схема программной части ИС представлена на рисунке 2. 


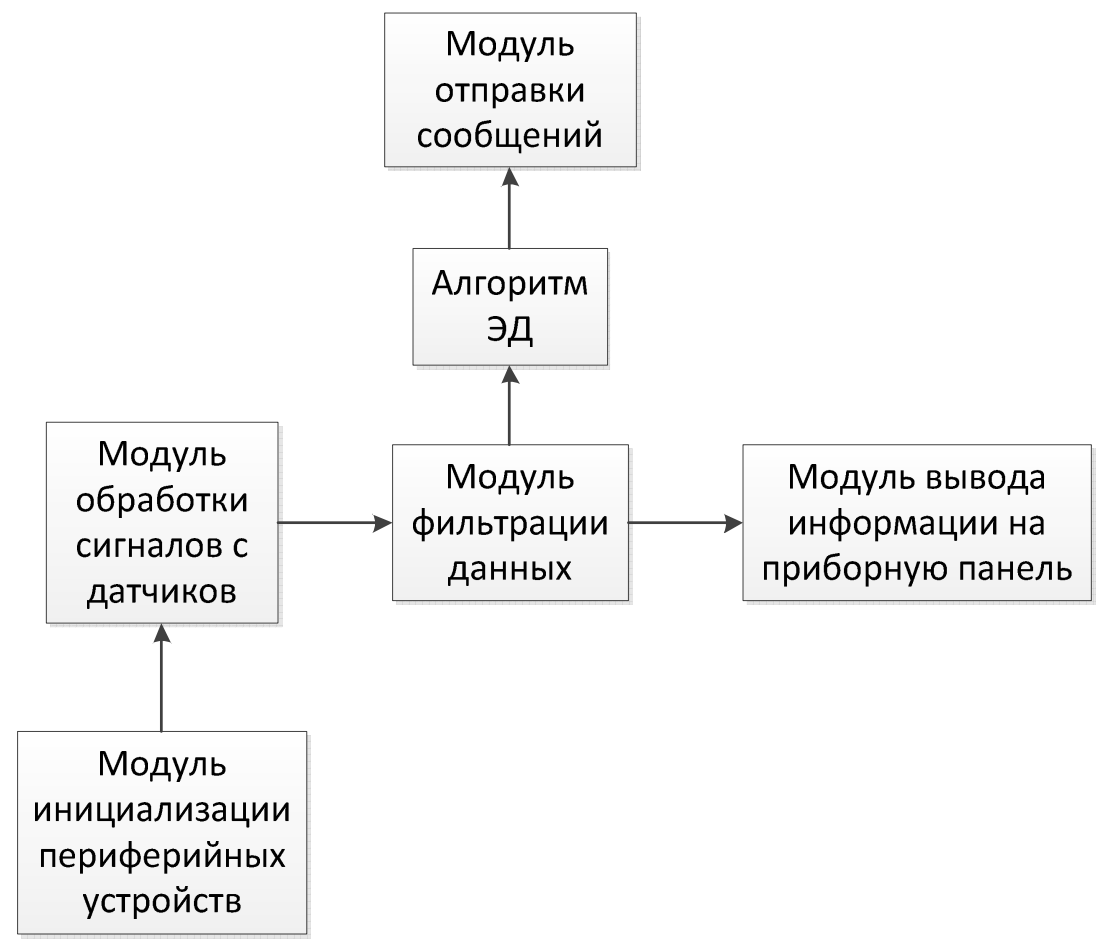

\section{Рисунок 2 - Структурная схема программной части ИС}

\section{4. Функциональная модель ИС}

Для визуального представления того, как функционирует система, составим функциональную схему ИС [11]. Чтобы составить схему, воспользуемся программой ERWIN Process Modeler. Данная программа строит модели систем по методологии IDEF0, предназначенной для рассмотрения логических отношений между работами, а не их временную последовательность. Разработанная функциональная схема представлена на рисунке 3 .

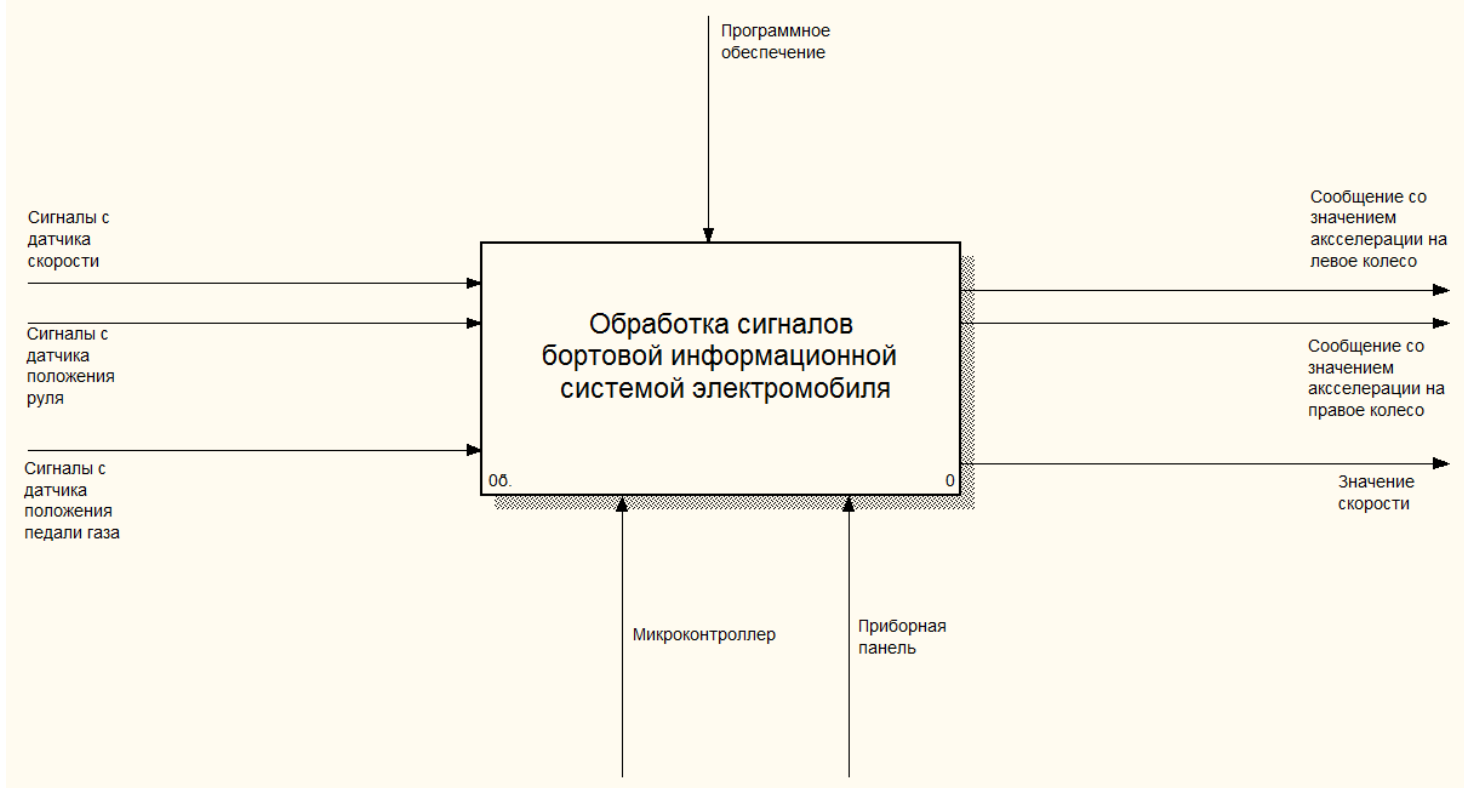

Рисунок 3 - Функциональная схема ИС 
Во всей модели входными данными являются электрические сигналы, приходящие с датчиков, выходными - сообщения, посылаемые по CAN шине, и выводимое на приборную панель значение скорости. Механизмом же выступает в основном микроконтроллер, он выполняет все задачи по расчету показателей и обработке данных. Управлением занимается программное обеспечение, записанное в микроконтроллер. От программного обеспечения, в конечном итоге, зависит работа всей системы, поэтому ему следует уделить особое внимание.

На рисунке 4 изображена декомпозированная функциональная схема, на рисунке 5 проиллюстрирован декомпозированный блок «Работа периферийных устройств».

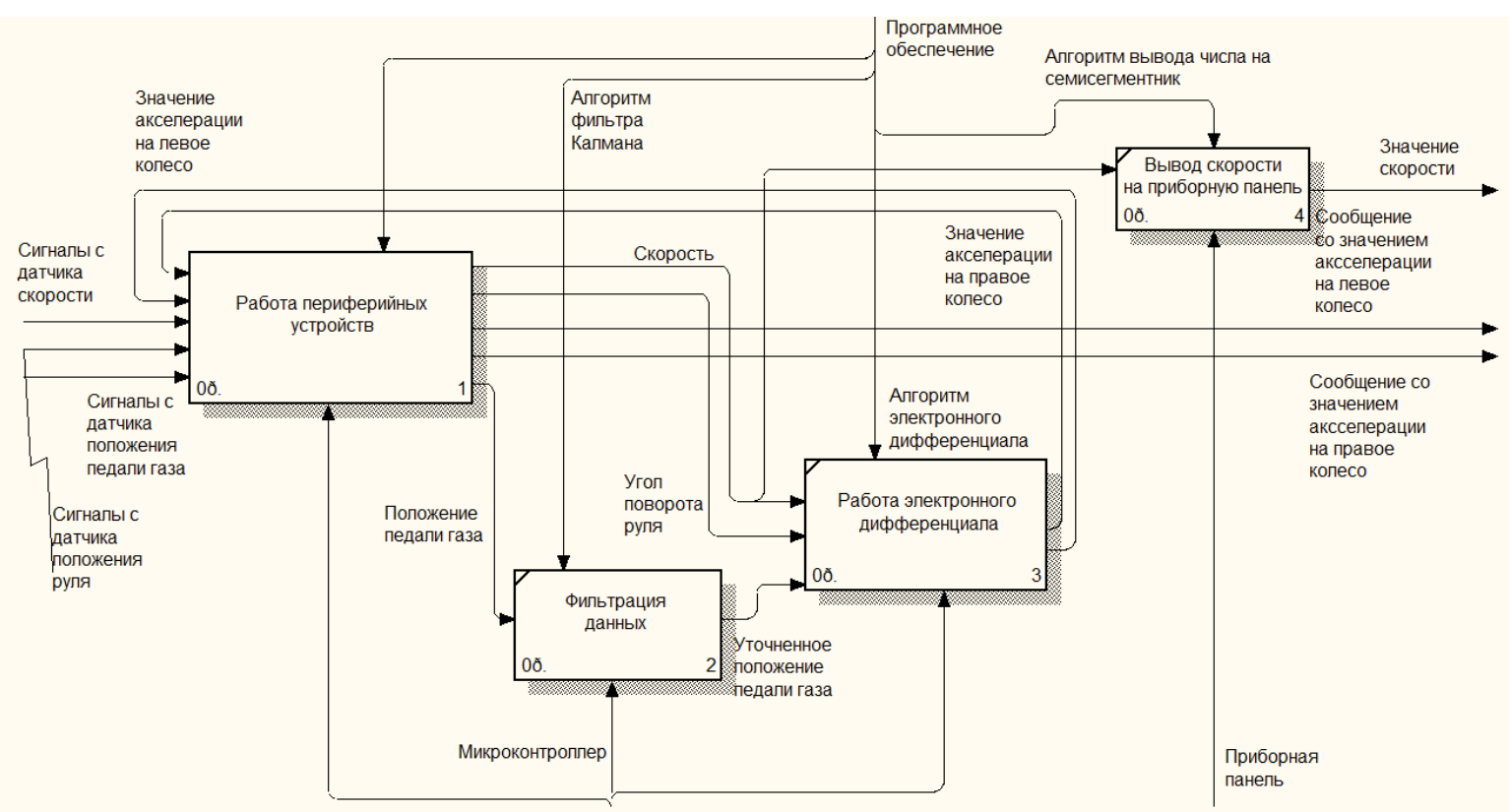

Рисунок 4 - Декомпозиция функциональной схемы

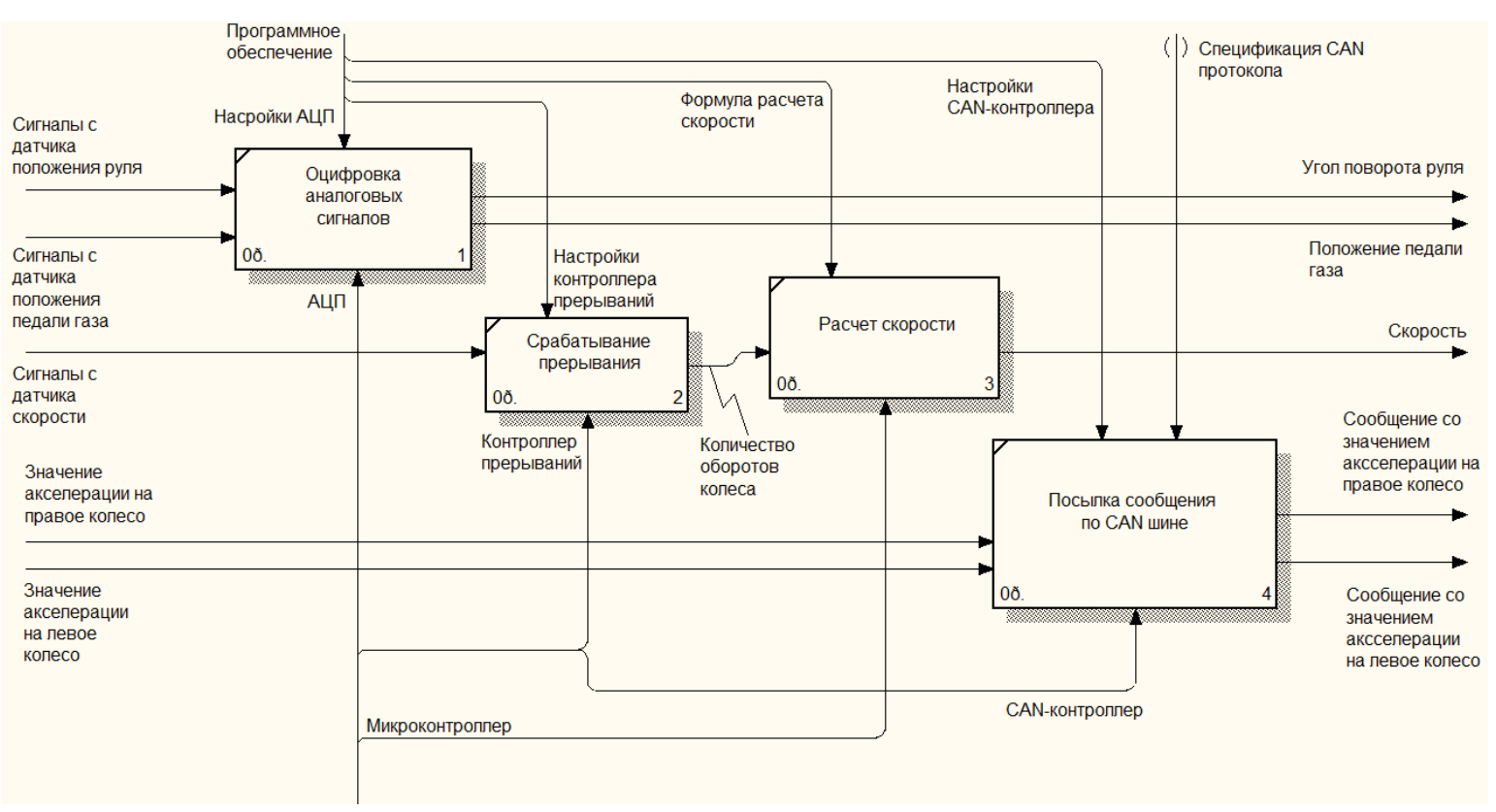

Рисунок 5 - Декомпозиция блока «Работа периферийных устройств» 
На первый взгляд, кажется, что схема довольно сложна и запутана, на самом деле все логично и тривиально. Более подробно каждый процесс будет последовательно рассмотрен в ходе разработки программного обеспечения.

\section{5. Выбор микроконтроллера}

Существует множество фирм, занимающихся производством микроконтроллеров. Они отличаются между собой набором выполняемых ими функций, но в основном все микроконтроллеры схожи по своему строению [12]. Они включают в себя множество периферийных устройств, такие как контроллеры еCAN, SCI, АЦП, контроллеры прерываний, множество портов ввода-вывода. Различие кроется в разрядности центрального процессора, количестве периферии и портов ввода-вывода. В ходе исследования был рассмотрен микроконтроллер TMS320F28335 компании Техаs Instruments. На рисунке 6 приведена функциональная схема этого микроконтроллера.

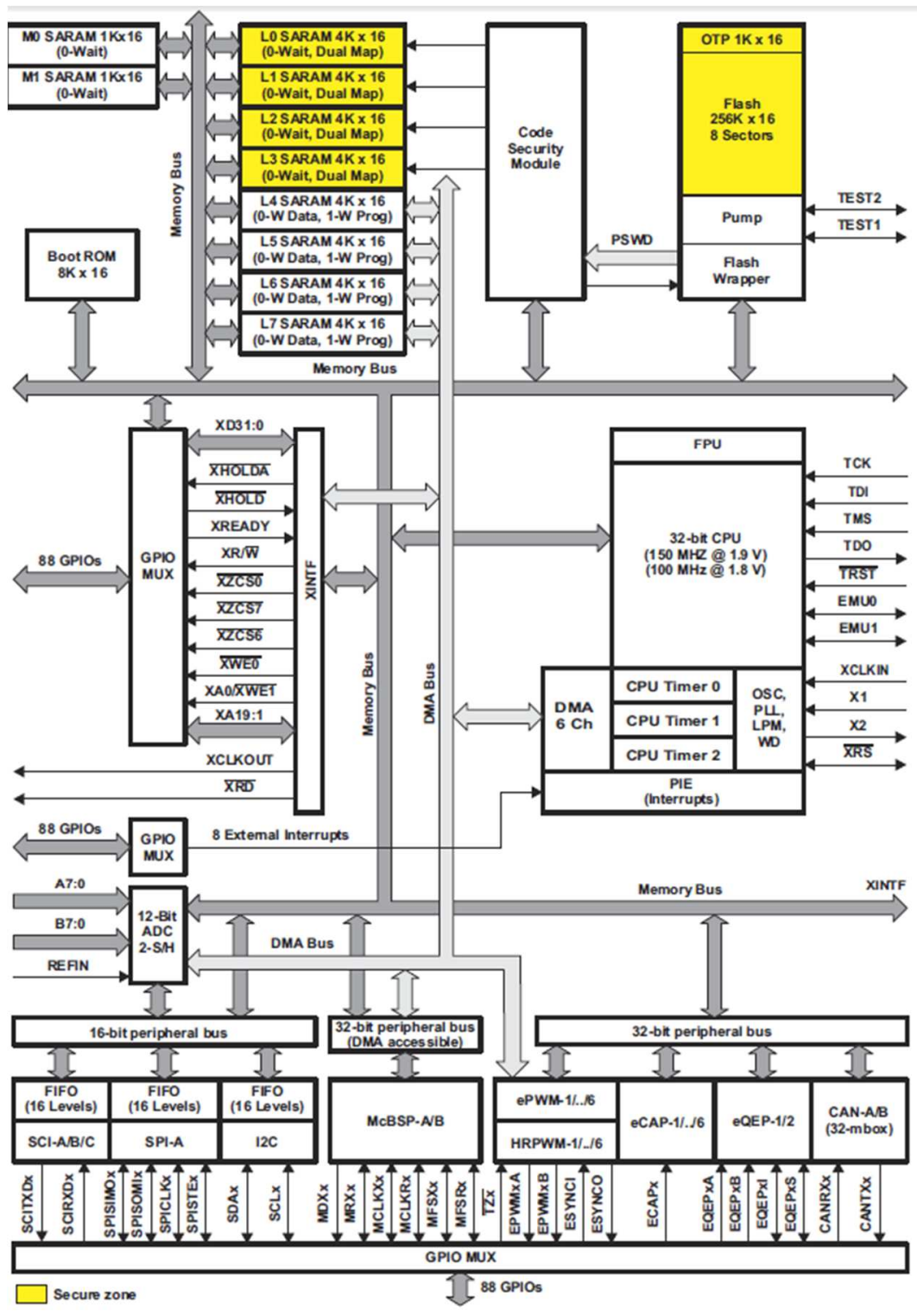

Рисунок 6 - Функциональная схема TMS320F28335 
Как уже было сказано, помимо МК в аппаратной части бортовой интеллектуальной системы состоят прочие электронные компоненты, необходимые для работы: транзисторы, резисторы, светодиоды, драйверы физического уровня и т.д. Можно было бы приобрести эти компоненты отдельно и самостоятельно изготовить плату-основу аппаратной части ИС. Но в целях экономии сил и средств был приобретен готовый встраиваемый модуль TE-TMS320F28335 (рисунок 7). Среди прочих данный модуль отличается низкой стоимостью, а также тем, что его производством занимается российская компания.

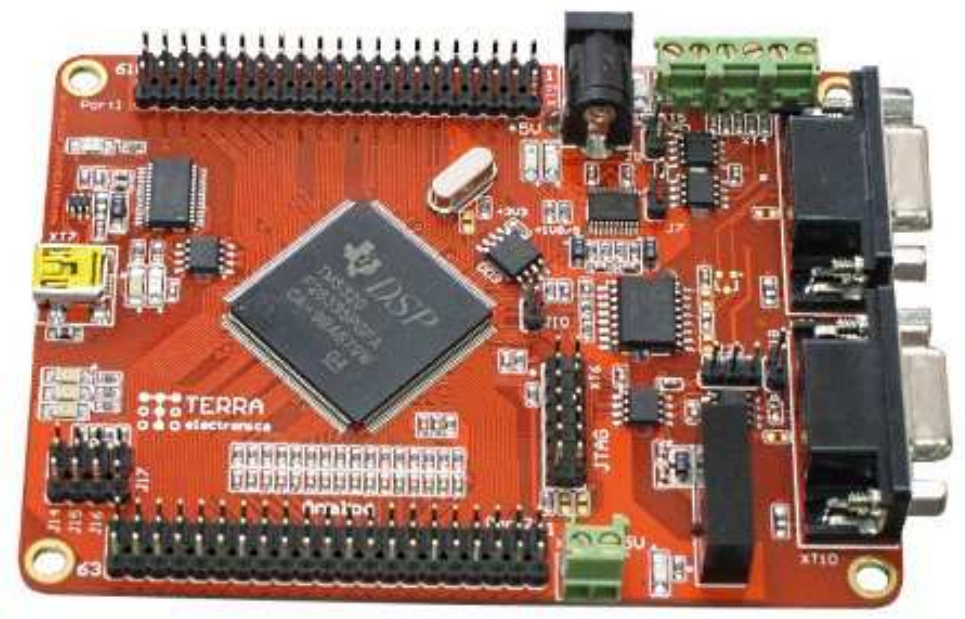

Рисунок 7 - Встраиваемый модуль TE-TMS320F28335

\section{6. Заключение}

В статье был проведен обзор области разработки интеллектуальной системы электромобиля, приведено описание основных понятий, касающихся строения бортовых компьютеров. Были проанализированы продукты-аналоги, описаны их особенности и недостатки. Сформулированы цель и задачи, выполнение которых поможет достичь поставленной цели. Были рассмотрены вопросы проектирования разрабатываемой системы, также были представлены структурная и функциональная схемы разрабатываемой ИС, и выбрана подходящая модель микроконтроллера, которая будет служить аппаратной базой будущей БИСЭ.

Произведенный обзор может быть использован при производстве собственных интеллектуальных систем электромобиля. Задачи, выполняемые предлагаемой информационной системой, могут быть значительно расширены. В перспективе система будет способна полностью контролировать движение автомобиля, учитывая все его характеристики и параметры.

\section{Список информационных источников}

[1] Алтунина А.В. Система автоматизации и контроля за продажами и производством автомобилей / А.В. Остроух, А.В. Алтунина // Автотранспортное предприятие. 2011. - №3. - С. 41-43. 
[2] Белоусова А.И. Подход к формированию многоуровневой модели мультиагентной системы с использованием миваров / А.И. Белоусова, О.О. Варламов, М.Н. Краснянский, А.В. Остроух // Перспективы науки - Тамбов. «ТМБПринт», 2011. № 5(20). - С. 57-61.

[3] Васюгова С.А. Исследование перспектив и проблем интеграции человека с компьютером: искусственный интеллект, робототехника, технологическая сингулярность и виртуальная реальность / А.В. Остроух, С.А. Васюгова, М.Н. Краснянский, А. Самаратунга // Перспективы науки. - Тамбов: «ТМБПринт», 2011. - № 4(19). - С. 109 - 112

[4] Варламов О.О. Анализ возможностей миварного подхода для систем искусственного интеллекта и современной робототехники / А.В. Остроух, М.Н. Краснянский, Т.Л. Давыдова, О.О. Варламов // Вестник ТГТУ. - 2011. - Т.17. - № 3. - С.687-694.

[5] Максимычев О.И. Система повышения эффективности автоматического управления землеройно-транспортными машинами / О.И. Максимычев, А.В. Остроух // Приборы и системы. Управление, контроль, диагностика. - М.: «Научтехлитиздат», 2005. - №5. - С. 63-66.

[6] Николаев А.Б. Информационные технологии в менеджменте и транспортной логистике: учебное пособие / А.Б. Николаев, А.В. Остроух. - Saint-Louis, MO, USA: Publishing House Science and Innovation Center, 2013. - 254 c. - ISBN 978-0615-67110-9.

[7] Остроух А.В. Основы построения систем искусственного интеллекта для промышленных и строительных предприятий: монография / А.В. Остроух. - М.: OОО «Техполиграфцентр», 2008. - 280 с. - ISBN 978-5-94385-033-2.

[8] Остроух А.В. Информационные технологии в научной и производственной деятельности / [ред. А.В. Остроух] - М: ООО "Техполиграфцентр", 2011. - 240 с. ISBN 978-5-94385-056-1.

[9] Остроух А.В. Ввод и обработка цифровой информации: учебник для нач. проф. образования / А.В. Остроух. - М.: Издательский центр «Академия», 2012. - 288 с. - ISBN 978-5-7695-9457-1.

[10] Остроух А.В. Системы искусственного интеллекта в промышленности, робототехнике и транспортном комплексе: монография / A.В. Остроух Красноярск: Научно-инновационный центр, 2013. - 326 с. - ISBN 978-5-90631410-9.

[11] Суркова Н.Е. Методы проектирования информационных систем / А.В. Остроух, H.Е. Суркова. - М.: РосHOУ, 2004. - 144 с. - ISBN 5-89789-021-8.

[12] Остроух А.В., Николаев А.Б., Сальный А.Г., Кухаренко В.Н. Общие принципы построения SCADA-систем // Автоматизация и управление в технических системах. - 2013. - № 2(4). - С. 8-12.

[13] Остроух А.В. Математическая модель связей в системе диагностики электрооборудования автомобилей / А.В. Остроух, А.А. Солнцев, О.Ф. Калухов, Г.Г. Ягудаев // Вестник МАДИ. - 2010. - Вып. 2(21). - С. 66-70. 